\title{
The role of pragmatic principles in resolving attachment ambiguities: Evidence from eye movements
}

\author{
MatThew J. TraXler \\ University of California, Davis, California \\ AND \\ LYN FraZIER \\ University of Massachusetts, Amherst, Massachusetts
}

\begin{abstract}
In an eyetracking experiment, participants read sentences that contained a prepositional phrase (PP) that could be attached to one of two preceding verbs. To understand the sentence, readers had to select which verb would serve as the host for the PP. In some of the sentences, the critical verbs and the PPs were part of a subordinate clause in which lexical and syntactic factors were expected to matter, but discourse factors favoring attachment of the material to positions where it would be relevant to the main assertion of the sentence were not expected to matter. In other sentences, the critical material was tested in main clause contexts in which the main assertion principle was predicted to apply. Hierarchical linear modeling showed that online attachment preferences were affected by clause type (main vs. subordinate). Specifically, the preference for a local verb over a distant verb was greater when the critical material appeared within a subordinate clause than when it appeared within a main clause. This pattern of results can be explained by the operation of the relativized relevance or main assertion principle, which in our sentences meant that participants favored attachment of the PP to the first verb over the second.
\end{abstract}

Syntactic ambiguity resolution lies at the center of much research on grammatical representation and sentence processing. Knowing how readers respond when sentences can be structured, at least temporarily, in more than one way helps to constrain accounts of how readers use grammatical and other information to develop interpretations of sentences in real time. Modifier attachment represents one type of ambiguity resolution problem that has received considerable attention in the past few years. This type of ambiguity is interesting to psycholinguists since when more than one configuration is possible for sentences that contain modifying expressions, a variety of factors could conceivably influence attachment preferences, including language-level statistical probabilities, lexically conditioned probabilities, the status of the phrase (argument vs. adjunct), the intrasentential and discourse context, prosodic factors, and so forth (see, e.g., Clifton, Speer, \& Abney, 1991). A careful determination of how and when these various factors affect the difficulty that readers have in processing sentences can lead to deeper insight into the workings of the human sentence parsing mechanism.

Many investigators have studied prepositional phrase (PP) attachment ambiguities, for a variety of different reasons (see, e.g., Clifton et al., 1991, and Schutze \& Gibson, 1999, for discussions of PP attachment ambiguities com- paring attachment to nouns with attachment to verbs and attachments as arguments with attachments as adjuncts). This article focuses on prepositional phrase attachment ambiguities like those in Sentence 1A.

\section{(1A) The baker delivered the bread that he checked to the store this morning.}

Although semantic information renders 1A unambiguous in the final interpretation, the status of the PP to the store is at least temporarily uncertain, since it is grammatically legal to attach the PP to either of the preceding verbs. If the order of the verbs were reversed, as in 1B, the sentence would still be grammatical, but the PP would attach to the lower verb.

\section{(1B) The baker checked the bread that he delivered to the store this morning.}

Determining what preference, if any, readers have for configuring sentences like $1 \mathrm{~A}$ and $1 \mathrm{~B}$ can help constrain parsing accounts built on the basis of other sentence types. For example, if readers always had greater difficulty processing the $\mathrm{PP}$ in sentences like $1 \mathrm{~A}$ than in sentences like $1 \mathrm{~B}$, a recency/low-attachment preference would be indicated, which would be consistent with parsing accounts such as the classic garden path theory (Frazier, 1979) 
or the integration cost hypothesis (Gibson, 1998, 2000), which imputes a cost for distant attachment that is not, however, dependent on ambiguity. By contrast, if readers had less difficulty processing the PP in main-clause contexts, like that in 1A, then a preference for having the more prominent main verb serve as the host for the modifier would be indicated. Such a preference would be more consistent with a heuristic such as relativized relevance, which states: "Other things being equal, e.g., all interpretations are grammatical, informative and appropriate to discourse, preferentially construe a phrase as being relevant to the main assertion of the sentence" (Frazier, 1990, p. 321).

The relativized relevance constraint was proposed because, in considering the attachment of optional constituents, the recency/low-attachment preference seems to be offset by a pressure to place the attachment wherever it makes the optional constituent most relevant to the main assertion of a speaker. Frazier and Clifton (2005) found strong evidence for this claim, although they dubbed the generalization the main assertion hypothesis. The main assertion hypothesis claims that, other things being equal, listeners/readers favor analyses that relate new material to the main assertion. Typically, the main assertion of a sentence is expressed in the main/matrix clause, not in a subordinate, relative, or complement clause. The main assertion is generally the most important contribution to discourse in an utterance. In Sentences $2 \mathrm{~A}$ and 2B, the missing verb phrase (VP) following did may take either the matrix VP (said...) or the embedded VP (went to Europe) as its antecedent. Frazier and Clifton (2005) showed that readers more strongly preferred a matrix VP antecedent for the elided VP (following did) in $2 \mathrm{~B}$ than they did in $2 \mathrm{~A}$. This supports the assumption of the main assertion hypothesis that the matrix VP is part of the main assertion and that, therefore, across a sentence boundary (like that in 2B), the discourse representation will predominate, because the syntactic representation will have become less accessible. However, within a sentence such as $2 \mathrm{~A}$, both the discourse representation and the syntactic representation will be highly accessible.

(2A) John said that Fred went to Europe and Mary did [ ] too.

(2B) John said that Fred went to Europe. Mary did [ ] too.

Could the main-assertion tendency in $2 \mathrm{~A}$ and $2 \mathrm{~B}$ really be due simply to the absence of the syntactic low-attachment preference? Probably not. Frazier and Clifton (2005) also reported a self-paced reading study that investigated the interpretation of examples like 3A and 3B.

(3A) Mary laughed after she made a joke about the supervisor. Then Tina did too.

(3B) After Mary laughed she made a joke about the supervisor. Then Tina did too.

Reading times for (3A) and (3B) did not differ. But regardless of whether the antecedent was contained in a sentence in which the main clause came first (as in 3A) or one in which the subordinate clause came first (as in 3B), readers chose the matrix VP as the antecedent for an elided VP roughly three quarters of the time - in 3A, 74\% of the time; in 3B, $70 \%$ of the time. This result is predicted by the main assertion hypothesis and cannot be explained by the absence or weakening of the late-closure/recency advantage.

Further, although the main assertion hypothesis generally assumes that the matrix VP is preferred as an antecedent, in some sentences with epistemic interpretations, this assumption does not hold.

(4A) The teacher thinks Mary smokes. Sam does [ ] too.

(4B) I think Mary smokes. Sam does [ ] too.

In examples like 4B, the matrix clause I think may receive an epistemic interpretation, meaning that it is understood as indicating only the degree of the speaker's commitment to the assertion expressed by the complement clause Mary smokes. Given this interpretation, 4B could be paraphrased as Apparently Mary smokes. The matrix clause in $4 \mathrm{~A}$, however, is not open to this interpretation, so the main assertion in 4A must include the matrix VP. Hence, the main assertion hypothesis predicts that the matrix VP will be chosen as the antecedent of the missing VP more often in $4 \mathrm{~A}$ than in $4 \mathrm{~B}$. This was confirmed by the answers participants chose for questions about the missing VP in a self-paced reading study.

In short, whether cast as the relativized relevance hypothesis or as the main assertion hypothesis, a pragmatic principle favors analyses in which new material is interpreted as being relevant to the main assertion rather than to other material-when, for example, new material is treated as presupposed rather than as asserted.

In the present study, we compared the effect of a phrase's appearance in a main clause with the effect of its appearance in a subordinate clause. Obviously, the main assertion hypothesis applies to main clauses (which typically express the main assertion of an utterance) but not to subordinate clauses. Consequently, more low/recent attachments are expected when the material to be attached appears within a relative clause, since recency will not be offset by relativized relevance. In main clauses, the two principles favor opposite analyses, and thus we would expect a weaker preference for a local attachment in main clauses.

Before turning to the experiment, we should point out that lexical preferences are known to influence PP attachment. In general, lexical preferences have been shown to influence reading times. For example, verbs that occur most often as transitive verbs are read faster when they occur with an object than when they occur without one. Often this relationship is modeled in terms of lexical preferences' guiding syntactic analysis (Ford, Bresnan, \& Kaplan, 1982; Trueswell, Tanenhaus, \& Kello, 1993, among many others; see Pickering \& Traxler, 2003, for a review). Sometimes, this relationship is cast instead in terms of lexical evaluation of a rapidly selected syntactic analysis (Frazier, 1989; Traxler, 2002, 2005). All such models expect that readers will rapidly eliminate syntactic analyses that are ungrammatical due to a verb's appearance in a syntactic frame that it does not allow (indeed, see Staub, Clifton, \& Frazier, 2005, for evidence that this 
information has a distinguished status in parsing). In the present study, each sentence used in the experiment contained two verbs that in principle could have provided attachment sites for the critical PP. In the Verb 1 and Verb 2 attachment conditions, verbs that could take a PP were rated as acceptable with the PP. Because the same verb occurred in the forced high- and forced low-attachment sentences, lexical and pragmatic preferences were controlled in these conditions: Each verb acted as its own control.

With respect to the main questions behind the experiments, what is critical about the lexical preferences is that an (optional) PP verb was compared with a verb that did not allow the PP for the two conditions. These conditions allow one to determine whether a forced high attachment takes longer to process than a forced low attachment. We presented some readers with sentences in which the critical material was part of the main clause (as in Sentences $1 \mathrm{~A}$ and $1 \mathrm{~B}$ ), whereas other readers received sentences in which the critical material was part of a subordinate clause. If the local attachment preference is universal and unaffected by other influences, then readers' behavior should be similar whether the critical material is part of a main clause or part of a subordinate clause. If, on the other hand, the relativized relevance constraint influences the processes readers use to attach PP arguments to preceding material, then local attachment should be more strongly favored in subordinate clauses than in main clauses.

\section{METHOD}

The experiment was designed to determine what preference, if any, readers had regarding where to attach a PP when two verbs were available to host the PP and the critical material appeared either within a subordinate clause, as in Sentences $5 \mathrm{~A}$ and $5 \mathrm{~B}$, or within a main clause, as in Sentences $5 \mathrm{C}$ and 5D (see below). When readers encounter a $\mathrm{PP}$, the memory trace of the local attachment site (Verb 2) should be stronger than the trace of the nonlocal site (Verb 1). This should lead to a preference for the local site over the nonlocal site. When the critical material is located within a subordinate clause, there is no countervailing influence from principles such as relativized relevance and main assertion to offset the recency/ low-attachment advantage. Assuming that material is more difficult to integrate across intervening discourse referents (see, e.g., Gibson, 1998), Verb 1 attachment should be more difficult and time consuming than Verb 2 attachment should be.

One account predicts no preference for sentences like $5 \mathrm{~A}-5 \mathrm{D}$, however. Assume that syntactic structures, especially verb-argument frames, are stored as part of the lexical representations of particular words (Ford et al., 1982; MacDonald, Pearlmutter, \& Seidenberg, 1994). A number of possible processing accounts are compatible with lexical association and activation of grammatical form. One such account, which we call the lexical filtering account, proposes that syntactic structures are activated to the extent that they are predicted by the presence of specific words or combinations of words, potentially adjusted by other influences such as the presence or absence of multiple possible referents in a visual or discourse context (Altmann \& Steedman, 1988; Tanenhaus, Spivey-Knowlton, Eberhard, \& Sedivy, 1995; Trueswell, Sekerina, Hill, \& Logrip, 1999).

On this account, sentences like 1A and 1B (and our experimental sentences below) are effectively unambiguous, because selection restrictions for verbs like checked immediately rule out the V2 attachment site (in 1A) and the V1 attachment site (in 1B). Note that, since all verbs allow locative PP modifiers, this account assumes that lexical statistics are kept at a fairly fine grain (because, although checked to the store is ungrammatical, checked at the store is fine).
An account in which the lexicon keeps statistics only at the generic PP level would not immediately eliminate the interpretation that the PP to the store attaches to checked, assuming that the verb checked can appear in a "+ direct object + (locative) PP" configuration. Regardless, if a preference for sentences like 5A-5D below were observed, it would falsify at least one version of the lexical filtering hypothesis. Alternatively, such a preference would narrow the range of possible answers to the grain size problem (Brysbaert \& Mitchell, 1996; Mitchell, 1987; Mitchell, Cuetos, Corley, \& Brysbaert, 1995). Specifically, a preference for one attachment over the other in either direction would mean that any statistics were computed at the level of generic PPs, rather than being computed separately for different PP subtypes (such as goal, agent, instrument, location, etc.). This is because if statistics were tabulated for different types of PPs, the probability of checked plus to (a goal PP) would be zero, and that attachment would never be considered. (Note, however, that it is possible to differentially weight lexically and syntactically defined probabilities such that the lexically impermissible interpretation would nonetheless be considered by the parser.)

\section{Participants}

A total of 252 undergraduates from the University of California at Davis participated in exchange for course credit. All were native English speakers with normal vision and hearing.

\section{Stimuli}

The test items comprised 28 sets of sentences like $5 \mathrm{~A}-5 \mathrm{D}$.

(5A) Before the baker delivered the bread that he checked to the store (on the corner), the customer stopped by for some donuts. (Verb 1 attachment, subordinate clause)

(5B) Before the baker checked the bread that he delivered to the store (on the corner), the customer stopped by for some donuts. (Verb 2 attachment, subordinate clause)

(5C) The baker delivered the bread that he checked to the store (early this morning.) (, but it was too late). (Verb 1 attachment, main clause)

(5D) The baker checked the bread that he delivered to the store (early this morning.) (, but it was too late). (Verb 2 attachment, main clause)

The material in parentheses indicates different versions of the items that were used in different subexperiments. (See the Appendix for a complete list of items.)

In half of the items, the PP was attached to the first verb (Verb 1 attachment); in the other half, the PP was attached to the second verb (Verb 2 attachment). The test sentences had the critical material in either a main or a subordinate clause. The end of the ambiguously attached PP was marked with a comma in half of the items; in the other half, the end of the PP was not explicitly marked with any punctuation. Thus, the design of the experiment was 2 (clause type: main vs. subordinate) $\times 2$ (attachment: PP attached to sentence's first verb vs. PP attached to sentence's second verb) $\times 2$ (puncation: end of PP marked by a comma vs. end of PP not explicitly marked by punctuation). ${ }^{1}$ Attachment was a within-participants variable, whereas clause type and punctuation were between-participants variables.

Because the data were collected as a series of subexperiments, four sets of experimental items were presented to participants in a between-subjects design. Thus, four separate groups of participants saw different sets of items embedded in different quantities and combinations of filler items.

The first group of 48 participants read 28 experimental items consisting of sentences starting with a subordinate clause, like Sentences 5A and 5B. In these sentences, a phrase like on the corner was present after the critical PP, and a comma was present after corner. Filler sentences included ambiguous counterparts to the sentences like 5A and 5B (such as The baker drove the bread that he delivered to the store ....) so that readers would not necessarily expect difficulty when they encountered a sentence with a structure like that of 
the experimental sentences. There were 105 filler sentences in all; 48 of them were from a syntactic priming experiment, and the other 57 were of various types (such as The old man that sold the house moved to an apartment).

A second group of 61 participants read the second set of 28 items. These items differed from the previous set in that a comma appeared immediately after the critical PP. These items were presented along with 24 sentences from an experiment on type coercion and 48 fillers of various types (such as My sister likes tuna fish sandwiches, although she would rather have soup and a salad).

The third group of 99 participants read the third set of 28 experimental items, which were like Sentences 5C and 5D. In these sentences, the critical material was part of a main clause and there was no punctuation immediately following the PP. As in the preceding versions, fillers included ambiguous items; 28 of the filler items came from an experiment that investigated context effects on type coercion. The remaining 38 fillers were of various types (such as Tuesday morning, the elementary school children read about Mexico).

The final group of 44 participants read the fourth set of 28 experimental items, which were like Sentences 5C and 5D except that a comma followed by a coordinate clause was added. Thus, the comma appeared immediately after the scoring region to the store. These items were presented to participants along with 40 three-sentence paragraphs taken from an experiment that investigated context effects on ambiguity resolution.

The four lists of items were presented to separate groups of participants in separate testing epochs. Within each epoch, the sentences were assigned to lists using a Latin square design. As a result, each participant saw equal numbers of sentences from each condition, and no participant saw more than one version of each item. Presentation order was individually randomized for each participant.

On two of the lists of items, the critical material appeared within a subordinate clause that preceded the main clause, whereas on the remaining lists, the critical material appeared within a main clause.

Length and frequency were matched across the Verb 1 and Verb 2 positions by reversing the order of the verbs between conditions.

To verify that the PP attachment solutions in the Verb 1 and Verb 2 attachment conditions matched our intuitions regarding their acceptability, we had 18 participants from the same pool as that of the participants in the eye-movement experiment rate the acceptability of the 28 sentences from the experiment. In this norming study, the $\mathrm{PP}$ arguments were presented with only one verb as potential host, as in $6 \mathrm{~A}$ and $6 \mathrm{~B}$.

(6A) The baker delivered the bread to the store.

(6B) The baker checked the bread to the store.

Participants were instructed to "Read each of the following sentences and decide whether it is an acceptable English sentence. To be acceptable, a sentence should be grammatical and make sense. For each sentence, report a number from 1 (highly acceptable) to 7 (highly unacceptable) that reflects how acceptable you think the sentence is." For the Verb 1 and Verb 2 conditions, sentences deemed acceptable (like $6 \mathrm{~A}$ ) received a mean rating of 1.6 , whereas the sentences deemed unacceptable (like $6 \mathrm{~B}$ ) received a mean rating of 5.3 $[t(27)=20.8, p<.0001]$.

\section{Procedure}

A Fourward Technologies dual-Purkinje-image eyetracker monitored participants' eye movements while they read sentences like $5 \mathrm{~A}-5 \mathrm{D}$. The tracker has angular resolution of $10^{\prime}$. The tracker monitored the gaze location of the participants' right eyes only, but viewing was binocular. A PC displayed materials on a VDU $70 \mathrm{~cm}$ from participants' eyes. The display comprised approximately four characters per degree of visual angle presented in Borland $\mathrm{C}$ default font. The location of each participant's gaze was sampled every millisecond, and the PC software recorded the tracker's output to establish the sequence of eye fixations and their start and finish times. At the beginning of the experiment, the experimenter seated the participant at the eyetracker and used a bite plate and headrests to minimize head movements. The tracker was then aligned and calibrated before the experiment began. After reading each sentence, the participant pressed a key. After at least 10 of the filler sentences, the participant responded to a comprehension question (the number of questions differed depending on the test epoch; the minimum number of questions was 10; the maximum, 20). Participants did not receive feedback on their responses. All of the participants whose data are reported in the analyses below scored at least $90 \%$ accuracy on the comprehension questions. Approximately 25 participants who scored below $90 \%$ accuracy had their data replaced by data from new participants. Between each trial, a pattern of boxes appeared on the computer screen along with a cursor that indicated the participant's current gaze location. If the tracker was misaligned, the experimenter recalibrated it before proceeding to the next trial.

\section{Analyses}

Four standard eye movement measures were computed for each participant. First-pass time represents the summed duration of all of a participant's fixations, beginning with the first fixation in a region and continuing until the participant's gaze left the region to the left or right. First-pass regressions include all of the saccades that crossed a region's left-hand boundary immediately following a first-pass fixation. Regression path time counts all of the fixations within a region until the participant fixated any material to the right of the scoring region. This measure includes refixations of preceding material and the scoring region itself. Total time is the sum of all fixation durations in a region, regardless of order.

We analyzed data from four scoring regions. The pretarget region starts at the beginning of a sentence and ends immediately following the second verb. The $P P$ region comprises the $\mathrm{PP}$ (e.g., to the store in $5 \mathrm{~A}-5 \mathrm{D})$. The PP region was analyzed as a whole because it is a linguistically defined region that disambiguates the sentence. It is possible that readers may have considered an infinitival complement analysis if their gaze had captured only the pretarget region and the word to. However, on the vast majority of those trials on which participants directly fixated the word to, that fixation served as the encoding fixation for the syntactically disambiguating determiner the. The string to the is inconsistent with an infinitival complement and so must be part of a goal PP, even though the exact goal may not be encoded at this point in time. To guard against the possibility that the infinitival versus the PP ambiguity influenced our results, we also analyzed a noun phrase (NP) region, which consisted of only the determiner and the noun within the disambiguating PP. The final posttarget region consisted of the two words that immediately followed the PP region. Analysis of the posttarget region is included mainly for completeness, since it may indicate whether effects lingered past the disambiguating region.

Each participant had up to 28 data points for each dependent measure in each scoring region. Missing data points were due to track loss or extremely short or extremely long fixations. Prior to determining fixation durations, an automatic procedure incorporated fixations shorter than $80 \mathrm{msec}$ into the largest fixation within one character. In the next stage, the procedure eliminated all individual fixations longer than $1,000 \mathrm{msec}$ and shorter than $80 \mathrm{msec}$. Subsequently, first-pass and total times shorter than $120 \mathrm{msec}$ were excluded from the analyses. Finally, any first-pass or total time exceeding 3,000 msec was excluded (except for those from the pretarget region, for which first-pass and total times exceeding 5,000 msec were excluded). These procedures together excluded $5.4 \%$ of the data: $2.4 \%, 3.7 \%$, and $10.0 \%$ of data from the analyses of the pretarget, $\mathrm{PP}$, and posttarget regions, respectively.

The data were analyzed using hierarchical linear modeling (HLM) (Raudenbush \& Bryk, 2002). The purpose of the HLM was to determine where readers preferred to attach the PP. The modeling was also used to assess whether readers preferred to attach the PP to the first or second verb and whether the degree of preference differed between main and subordinate clause sentences. (A more detailed description of how HLM can be used to analyze reading time data can be found in Blozis \& Traxler, 2007.) 
One model was fitted for each dependent measure in each scoring region. In the by-participants models (see Model 1 below), first-pass times, first-pass regressions, regression path times, and total time outcomes were considered a function of attachment (PP attached to the first verb vs. to the second verb). This constituted the first level of the model. To test the effects of clause type, we included interactions between clause type (main vs. subordinate) and attachment condition (Verb 1 vs. Verb 2) at the second level of the model. Finally, it is important to note that estimation of the Level 1 and Level 2 associations occurred simultaneously (Raudenbush \& Bryk, 2002). In the by-items models, all of the predictors were entered at the first level of the model.

\section{Model 1}

Level 1: Participant $i$ 's reaction time (RT) for Sentence $j=$ $\beta_{0 i}+\beta_{1 i}$ (attachment to Verb 1$)+\varepsilon_{i j}$

Level 2: $\beta_{0 i}=\gamma_{00}+\gamma_{01}$ (clause type $)_{i}+u_{0 i}$ $\beta_{1 i}=\gamma_{10}+\gamma_{11}$ (clause type) ${ }_{i}+u_{1 i}$

$\beta_{0 i}$ is the mean reading time for Participant $i$ in the baseline condition (e.g., when the PP attaches to Verb 2, and the sentence has a subordinate clause).

$\beta_{1 i}$ is the mean change from baseline for Participant $i$ when the PP attaches to Verb 1.

$\varepsilon_{i j}$ is the error for Participant $i$, Sentence $j$.

$\gamma_{00}$ is the grand mean RT when clause type is set to 0 (subordinate clause condition).

$\gamma_{01}$ is the change in mean RT when clause type is set to 1 (main clause condition).

$\gamma_{10}$ is the average change in the magnitude of the Verb 1 attachment effect when clause type is set to 0 (subordinate clause sentences). $\gamma_{11}$ is the average change in the magnitude of the Verb 1 attachment effect when clause type is set to 1 (main clause sentences).

$u_{0 i}$ and $u_{1 i}$ are the errors for the Level 2 intercept and slope.

\section{RESULTS}

Table 1 presents mean values for the four dependent measures by scoring region and condition. Tables $2-5$ present the results of the HLM analyses for the four scoring regions separately.

\section{Pretarget Region}

As Table 2 shows, there were no main effects of attachment and no interactions of attachment and clause type in the pretarget region.

\section{PP Region}

In the PP region, main effects of attachment, with Verb 1 attachment being more difficult than Verb 2 attachment, occurred in all of the dependent measures except first-pass regressions. There was a trend toward an interaction of clause type and attachment in the regression path time data and a fully significant interaction in the total time data (see Table 3). This interaction reflects greater Verb 1 attachment versus Verb 2 attachment differences in the subordinate clause sentences than in the main clause sentences (110 vs. $42 \mathrm{msec}$, respectively, in the total time data).

Table 1

Mean Values for First-Pass Time, First-Pass Regressions, Regression Path Time, and Total Time for the Pretarget, Prepositional Phrase, and Posttarget Scoring Regions by Condition

\begin{tabular}{|c|c|c|c|c|}
\hline Region & $\begin{array}{c}\text { First-Pass } \\
\text { Time (msec) }\end{array}$ & $\begin{array}{c}\text { First-Pass } \\
\text { Regressions (\%) }\end{array}$ & $\begin{array}{c}\text { Regression } \\
\text { Path Time (msec) }\end{array}$ & $\begin{array}{c}\text { Total } \\
\text { Time }(\mathrm{msec})\end{array}$ \\
\hline \multicolumn{5}{|l|}{ Pretarget } \\
\hline \multicolumn{5}{|c|}{ Main Clause Sentences } \\
\hline V1 attached & 2,136 & - & - & 2,538 \\
\hline V2 attached & 2,146 & - & - & 2,574 \\
\hline \multicolumn{5}{|c|}{ Subordinate Clause Sentences } \\
\hline V1 attached & 2,062 & - & - & 2,510 \\
\hline V2 attached & 2,043 & - & - & 2,488 \\
\hline \multicolumn{5}{|l|}{ Prepositional Phrase } \\
\hline \multicolumn{5}{|c|}{ Main Clause Sentences } \\
\hline V1 attached & 525 & 18.2 & 701 & 697 \\
\hline V2 attached & 494 & 16.9 & 665 & 655 \\
\hline \multicolumn{5}{|c|}{ Subordinate Clause Sentences } \\
\hline V1 attached & 516 & 21.1 & 743 & 760 \\
\hline V2 attached & 472 & 19.3 & 657 & 650 \\
\hline \multicolumn{5}{|l|}{ Noun Phrase } \\
\hline \multicolumn{5}{|c|}{ Main Clause Sentences } \\
\hline V1 attached & 448 & 23.2 & 623 & 566 \\
\hline V2 attached & 421 & 21.3 & 582 & 533 \\
\hline \multicolumn{5}{|c|}{ Subordinate Clause Sentences } \\
\hline V1 attached & 437 & 27.6 & 678 & 619 \\
\hline V2 attached & 411 & 25.8 & 588 & 538 \\
\hline \multicolumn{5}{|l|}{ Posttarget } \\
\hline \multicolumn{5}{|c|}{ Main Clause Sentences } \\
\hline V1 attached & 396 & 7.6 & 466 & 485 \\
\hline V2 attached & 403 & 7.6 & 472 & 488 \\
\hline \multicolumn{5}{|c|}{ Subordinate Clause Sentences } \\
\hline V1 attached & 457 & 10.3 & 555 & 554 \\
\hline V2 attached & 447 & 8.0 & 528 & 534 \\
\hline
\end{tabular}

Note-Because it is not possible to regress from the pretarget region, there are no first-pass regressions in that region, and regression path time is equal to first-pass time. V, verb. 
Table 2

Analysis of the Pretarget Region

\begin{tabular}{|c|c|c|c|c|c|c|c|c|}
\hline \multirow[b]{2}{*}{ Results } & \multicolumn{2}{|c|}{$\begin{array}{l}\text { First-Pass } \\
\text { Time }(\mathrm{msec})\end{array}$} & \multicolumn{2}{|c|}{$\begin{array}{c}\text { First-Pass } \\
\text { Regressions } \\
\end{array}$} & \multicolumn{2}{|c|}{$\begin{array}{l}\text { Regression } \\
\text { Path Time } \\
(\mathrm{msec}) \\
\end{array}$} & \multicolumn{2}{|c|}{$\begin{array}{c}\text { Total } \\
\text { Time }(\mathrm{msec})\end{array}$} \\
\hline & $M$ & $S E$ & $M$ & $S E$ & $M$ & $S E$ & $M$ & $S E$ \\
\hline \multicolumn{9}{|l|}{ By Participants } \\
\hline $\begin{array}{l}\text { Intercept: RT in the V2 attached, subordinate } \\
\text { clause condition }\end{array}$ & 2,039 & 63 & - & - & - & - & 2,481 & 79.8 \\
\hline Main clause effect & 106 & 74.3 & - & - & - & - & 87.2 & 99.4 \\
\hline Overall V1 attachment effect & 21.5 & 40.4 & - & - & - & - & 30.2 & 60.3 \\
\hline Clause type effect on V1 attachment coefficient & -28.3 & 47.1 & - & - & - & - & -61.0 & 71.7 \\
\hline \multicolumn{9}{|l|}{ By Items } \\
\hline $\begin{array}{l}\text { Intercept: } \mathrm{RT} \text { in the } \mathrm{V} 2 \text { attached, subordinate } \\
\text { clause condition }\end{array}$ & 2,040 & 73.8 & - & - & - & - & 2,467 & 108 \\
\hline Main clause effect & 119 & 106 & - & - & - & - & 106 & 145 \\
\hline Overall V1 attachment effect & 17.4 & 33 & - & - & - & - & 10.2 & 55.4 \\
\hline Clause type effect on V1 attachment coefficient & -38.2 & 40.9 & - & - & - & - & -61.9 & 70.3 \\
\hline
\end{tabular}

Note-Because readers cannot regress from this region, no analyses are possible, and regression path time is equivalent to first-pass time. $\mathrm{V}$, verb.

Table 3

Analysis of the Prepositional Phrase Region

\begin{tabular}{|c|c|c|c|c|c|c|c|c|}
\hline \multirow[b]{2}{*}{ Results } & \multicolumn{2}{|c|}{$\begin{array}{l}\text { First-Pass } \\
\text { Time }(\mathrm{msec})\end{array}$} & \multicolumn{2}{|c|}{$\begin{array}{l}\text { First-Pass } \\
\text { Regressions }\end{array}$} & \multicolumn{2}{|c|}{$\begin{array}{l}\text { Regression } \\
\text { Path Time } \\
(\mathrm{msec})\end{array}$} & \multicolumn{2}{|c|}{$\begin{array}{c}\text { Total } \\
\text { Time }(\mathrm{msec})\end{array}$} \\
\hline & $M$ & $S E$ & $M$ & $S E$ & $M$ & $S E$ & $M$ & $S E$ \\
\hline \multicolumn{9}{|l|}{ By Participants } \\
\hline $\begin{array}{l}\text { Intercept: RT in the V2 attached, subordinate } \\
\text { clause condition }\end{array}$ & 503 & 12.2 & 19.1 & 1.50 & 657 & 21.8 & 650 & 21.3 \\
\hline Main clause effect & 16.3 & 15.4 & -3.21 & 2.10 & 7.63 & 26.8 & 5.38 & 26.7 \\
\hline Overall V1 attachment effect & $44.4^{* *}$ & 12.9 & 3.25 & 2.46 & $81.2^{* *}$ & 18.9 & $109^{* *}$ & 20.4 \\
\hline Clause type effect on V1 attachment coefficient & -15.3 & 16.7 & 0.63 & 3.10 & $-45.8^{\dagger}$ & 24.5 & $-67.3^{* *}$ & 23.8 \\
\hline \multicolumn{9}{|l|}{ By Items } \\
\hline $\begin{array}{l}\text { Intercept: } \mathrm{RT} \text { in the } \mathrm{V} 2 \text { attached, subordinate } \\
\text { clause condition }\end{array}$ & 505 & 15.2 & 18.4 & 1.14 & 655 & 21.4 & 651 & 22.5 \\
\hline Main clause effect & 13.5 & 11.9 & $-3.51^{*}$ & 1.37 & 6.73 & 20.3 & 0.54 & 24.4 \\
\hline Overall V1 attachment effect & $42.4^{* *}$ & 13.5 & $6.45^{*}$ & 2.43 & $79.8^{* *}$ & 29.9 & $107^{* *}$ & 28.5 \\
\hline Clause type effect on V1 attachment coefficient & -14.6 & 18.2 & -0.01 & 2.78 & $-48.8^{\dagger}$ & 29.2 & $-67.8^{*}$ & 33.7 \\
\hline
\end{tabular}

Note-V, verb. ${ }^{*} p<.05 .{ }^{* *} p<.01 . \quad{ }^{*} .05<p<.10$.

Table 4

Analysis of the Noun Phrase Region

\begin{tabular}{|c|c|c|c|c|c|c|c|c|}
\hline \multirow[b]{2}{*}{ Results } & \multicolumn{2}{|c|}{$\begin{array}{l}\text { First-Pass } \\
\text { Time (msec) }\end{array}$} & \multicolumn{2}{|c|}{$\begin{array}{l}\text { First-Pass } \\
\text { Regressions }\end{array}$} & \multicolumn{2}{|c|}{$\begin{array}{l}\text { Regression } \\
\text { Path Time } \\
(\mathrm{msec})\end{array}$} & \multicolumn{2}{|c|}{$\begin{array}{c}\text { Total } \\
\text { Time }(\mathrm{msec})\end{array}$} \\
\hline & $M$ & $S E$ & $M$ & $S E$ & $M$ & $S E$ & $M$ & $S E$ \\
\hline \multicolumn{9}{|l|}{ By Participants } \\
\hline $\begin{array}{l}\text { Intercept: RT in the V2 attached, subordinate } \\
\text { clause condition }\end{array}$ & 412 & 10.5 & 25.8 & 2.09 & 587 & 20.6 & 539 & 17.7 \\
\hline Main clause effect & 9.72 & 13.4 & $-4.63^{\dagger}$ & 2.75 & -3.92 & 25.6 & -6.28 & 22.3 \\
\hline Overall V1 attachment effect & $24.2^{*}$ & 11.2 & 1.44 & 2.31 & $88.5^{* *}$ & 20.4 & $79.7^{* *}$ & 16.8 \\
\hline Clause type effect on V1 attachment coefficient & 4.87 & 14.9 & 0.39 & 2.80 & $-49.4^{*}$ & 25.7 & $-44.8^{*}$ & 20.0 \\
\hline \multicolumn{9}{|l|}{ By Items } \\
\hline $\begin{array}{l}\text { Intercept: } \mathrm{RT} \text { in the V2 attached, subordinate } \\
\text { clause condition }\end{array}$ & 412 & 13.1 & 25.8 & 1.89 & 585 & 19.0 & 541 & 20.8 \\
\hline Main clause effect & 9.44 & 11.8 & $-5.06^{* *}$ & 1.95 & -4.54 & 23.5 & -8.56 & 18.9 \\
\hline Overall V1 attachment effect & $24.3^{*}$ & 12.5 & 1.56 & 3.21 & $89.9^{* *}$ & 23.8 & $79.0^{* *}$ & 24.3 \\
\hline Clause type effect on V1 attachment coefficient & 3.14 & 14.8 & 0.24 & 3.24 & $-53.9^{*}$ & 26.8 & $-45.8^{\dagger}$ & 28.1 \\
\hline
\end{tabular}

Note-V, verb. $\quad{ }^{*} p<.05 . \quad{ }^{* *} p<.01 . \quad{ }^{\dagger} .05<p<.10$. 
Table 5

Analysis of the Posttarget Region

\begin{tabular}{|c|c|c|c|c|c|c|c|c|}
\hline \multirow[b]{2}{*}{ Results } & \multicolumn{2}{|c|}{$\begin{array}{l}\text { First-Pass } \\
\text { Time }(\mathrm{msec})\end{array}$} & \multicolumn{2}{|c|}{$\begin{array}{l}\text { First-Pass } \\
\text { Regressions }\end{array}$} & \multicolumn{2}{|c|}{$\begin{array}{c}\text { Regression } \\
\text { Path Time } \\
(\mathrm{msec})\end{array}$} & \multicolumn{2}{|c|}{$\begin{array}{c}\text { Total } \\
\text { Time }(\mathrm{msec})\end{array}$} \\
\hline & $M$ & $S E$ & $M$ & $S E$ & $M$ & $S E$ & $M$ & $S E$ \\
\hline \multicolumn{9}{|l|}{ By Participants } \\
\hline $\begin{array}{l}\text { Intercept: } \mathrm{RT} \text { in the } \mathrm{V} 2 \text { attached, subordinate } \\
\text { clause condition }\end{array}$ & 449 & 11.7 & 7.99 & 0.95 & 529 & 16.1 & 535 & 14.7 \\
\hline Main clause effect & $-45.9^{* *}$ & 15.4 & -0.39 & 1.34 & $-57.0^{* *}$ & 22.0 & $-49.0^{* *}$ & 19.1 \\
\hline Overall V1 attachment effect & 9.50 & 11.9 & 2.35 & 1.51 & 25.8 & 19.6 & 21.3 & 14.5 \\
\hline Clause type effect on V1 attachment coefficient & -13.9 & 15.6 & -2.53 & 1.88 & -29.2 & 24.4 & -20.3 & 18.3 \\
\hline \multicolumn{9}{|l|}{ By Items } \\
\hline $\begin{array}{l}\text { Intercept: } \mathrm{RT} \text { in the } \mathrm{V} 2 \text { attached, subordinate } \\
\text { clause condition }\end{array}$ & 452 & 18.0 & 7.99 & 1.43 & 529 & 23.7 & 539 & 18.2 \\
\hline Main clause effect & $-46.0^{* *}$ & 16.8 & -0.42 & 1.58 & $-56.3^{* *}$ & 23.1 & $-51.2^{*}$ & 21.2 \\
\hline Overall V1 attachment effect & 7.27 & 14.0 & 2.36 & 1.50 & 23.6 & 24.0 & 18.9 & 16.0 \\
\hline Clause type effect on V1 attachment coefficient & -13.7 & 14.7 & -2.54 & 1.89 & -30.1 & 21.0 & -18.5 & 18.6 \\
\hline
\end{tabular}

Note-V, verb. ${ }^{*} p<.05 .{ }^{* *} p<.01$.

\section{NP Region}

In the NP region, main effects of attachment occurred in all of the dependent measures except first-pass regressions. The interaction of clause type and attachment was significant in the regression path time and total time data (see Table 4), although the by-items total time result did not reach the .05 level. The overall pattern was the same as in the larger PP region. The Verb 1-Verb 2 attachment difference was roughly twice as large in the subordinate clause sentences than in the main clause sentences in regression path time (about $90 \mathrm{msec}$ vs. about $40 \mathrm{msec}$ in regression path time and about $80 \mathrm{msec}$ vs. about $30 \mathrm{msec}$ in total time).

\section{Posttarget Region}

Analyses of the posttarget region produced only an effect of clause type, with subordinate clause sentences having shorter processing times than their main clause counterparts.

\section{DISCUSSION}

The experiment tested readers' responses to PPs in subordinate and main clauses in which two verbs could have hosted the modifier. HLM tested for attachment preferences and for moderating effects of clause type on attachment preference. In the first-pass data from the PP region, a general increase in processing difficulty was observed when the PP attached to the first verb (with analogous effects in the NP subregion). There was no indication from the HLM that the first-pass preference in the PP region was moderated by clause type. However, an interaction in the regression path data in the PP and NP scoring regions suggests that clause type had a fairly rapid effect on the degree of preference for local attachment. The total time data also indicates that participants had an overall preference to attach the PP to the second verb, but the degree of preference was affected by clause type. If the PP and the preceding verbs were part of a subordinate clause, readers had greater difficulty attaching the PP to the first verb. If the PP and the preceding verbs were part of a main clause, the degree of preference for attaching the PP to the second verb was reduced.

\section{Lexical Filtering?}

Two aspects of the present findings are difficult to reconcile with a strong version of the lexical-filtering hypothesis. The first is that the degree of preference for the local verb changed as the PPs moved from subordinate to main clauses. Because the verbs, their ordering, and the prepositions and nouns with which they appeared were identical across conditions, the lexical information available to readers was also identical across conditions. If attachment preferences were determined solely by lexically conditioned probabilities, then lexical filtering would provide no explanation for the difference in degree of preference across main and subordinate clauses. To account for the results within a lexical-filtering framework, one would have to assume that separate sets of statistics are tabulated for the same lexical items, one for when the verb appears in a main clause and another for when it appears in a subordinate clause. Of course, it is possible that a model with just the right mix of lexical and structural constraints could account for the data (for accounts of this general sort, see Altmann \& Steedman, 1988; Jackendoff, 2007; MacDonald et al., 1994).

The second aspect of the results that is difficult to reconcile with lexical filtering is the presence of any preference at all for sentences like 5A-5D. If lexical information alone governed the activation of various syntactic structures, only one attachment site would be available, and no processing difficulty would ensue (assuming that the attachment resulted in a plausible interpretation). The finding of increased processing time for Verb 1 attachment when the PP appeared in a subordinate clause suggests that participants tried the Verb 2 attachment solution first on a substantial proportion of trials, even when it was ruled out by the second verb's selection restrictions. Of course, it is impossible to rule out a version of the lexical-filtering account in which statistics are kept at a very fine grain or at the level of generic PPs (in which case, lexical properties would not immediately rule out attachment to either verb). It is likely that 
attachment preferences are set by a complex combination of factors, including the interaction of clause type, PP type, nouns within the PP, co-occurrence probabilities of the two candidate verbs, and so forth.

Hence, we conclude only that in the types of sentences tested in these experiments, lexical information by itself did not govern PP attachment preferences or initial interpretation. In this respect, the present results reinforce the conclusions of other studies that have also suggested that lexical information does not govern initial attachment (see, e.g., Traxler, Pickering, \& Clifton, 1998; Van Gompel, Pickering, \& Traxler, 2001). The present results also reinforce the conclusions of studies that have suggested the importance of discourse and pragmatic effects on attachment resolution; for example, pragmatic inferences about the purpose of a modifying expression can change or eliminate a simplicity preference in sentences in which a verb and a noun are available to host a PP (Altmann \& Steedman, 1988; Crain \& Steedman, 1985; Tanenhaus et al., 1995; Taraban \& McClelland, 1988; Trueswell et al., 1999).

\section{Implicit Prosodic Effects?}

One possibility that we have not yet considered is that the length of the PP relative to the length (or prosodic weight) of the preceding constituent might have influenced attachment preferences (see Fodor, 1998, for related proposals). When the PP attaches to the first verb (deliver in 7A), the first verb takes a long argument (the bread that he checked) followed by a short one (to the store). By contrast, when the PP attaches to the second verb, the long argument is not followed by a short one since the PP is contained within the long argument. Generally, the short-before-long order is preferred. Consequently, length considerations, like recency considerations, might favor attachment of the PP to the second verb. Whether lengthbased ordering preferences might be stronger in some sentences than in others is not clear. It is plausible that such preferences are strongest in the sentence-final positionat least, this is what would be expected given that long constituents are moved to the periphery (to the end of the sentence in right-branching languages like English, but to the beginning of the sentence in left-branching languages like Japanese). But this would incorrectly predict a stronger Verb 2 attachment preference in main clause sentences than in subordinate clause sentences.

\section{Integration Cost?}

The present results also suggest that integration cost (Gibson, 1998, 2000) is not the sole factor determining PP attachment preferences. (We take up other aspects of Gibson's SPLT/DLT account in greater detail below.) If integration cost were the sole factor, then Verb 2 attachment should have been easier across the board. Integration cost may have affected processing difficulty, but minimally, any negative influence of decay or interference from discourse entities introduced between the first verb and the modifier must have been counteracted to some extent by some other factor or factors favoring the nonlocal attachment site. A reviewer pointed out to us that in the model, subordinate clauses impose a greater memory cost than do main clauses, and thus an interaction of memory cost and distance might be involved. Although in principle one could devise such a model, it is difficult to see how the distant attachment site could be cheaper than the recent site in either context. So at best, the absolute cost of the distant site would seem to be affected by context. Any account of attachment processing will have to incorporate a set of principles to explain when recency should dominate and when other factors will counteract it, as they did in the main clause cases reported here. In general, accounts of PP processing should incorporate both structural principles, which are required to explain recency preferences for some sentence types, and pragmatic or discourse principles, which are required to explain discourse preferences as well as how, when, and why structure-based preferences can be mitigated. Finally, we should note that some current accounts are not specific enough to generate predictions for the types of sentences tested here (see, e.g., Traxler et al., 1998; Van Gompel, Pickering, \& Traxler, 2000, 2001).

\section{Other Attachment Findings}

To what extent are the present findings consistent with previous work on attachment preferences? First, we would note that many experiments on other attachment ambiguities have turned up cases in which readers had no preference for either a local or a more prominent attachment site (see, e.g., Traxler et al., 1998; Van Gompel et al., 2000, 2001). In relative clause attachment, for example, English speakers do not have a strong preference for either of two possible nouns when the sentence context consists of an NP-of-NP configuration. Local attachment preferences are observed when different modifier types are used (e.g., PPs vs. relative clauses) or when semantic properties of the host NP are manipulated to create a theta domain boundary between the first and the second noun (see De Vincenzi \& Job, 1993, 1995; Frazier \& Clifton, 1996; Gilboy, Sopena, Clifton, \& Frazier, 1995; for a review, see Fodor, 2002). These studies are similar to the present one in that no single factor dominated readers' preferences. Instead, a combination of influences led to the final observed preference (or lack thereof). Looking at three site attachment ambiguities, Gibson, Pearlmutter, Canseco-Gonzalez, and Hickok (1996) found a recency preference as well as a preference for high attachment in both Spanish and English, as predicted by relativized relevance (although in the Gibson et al., 1996, study, the principle favoring high attachment was cast as a "predicate proximity" principle). Interestingly, in both languages, the intermediate attachment site was dispreferred, being favored by neither syntactic nor discourse factors.

Pearlmutter and Gibson (2001) argued that adjuncts modifying VPs, in sharp contrast with relative clause attachment, show only a recency advantage, with the lowest of three clauses being the most preferred and the highest clause being the least preferred attachment site for an adverbial clause. Thus, in contrast with modifiers of NPs, for which the intermediate attachment site is dispreferred, the intermediate site is the second most preferred attachment site for modifiers of VPs. In their first experiment, Pearlmutter and Gibson tested sentences like this one: 
(7) The newspaper would print that the director had appreciated that the author had written the screenplay next May before any casting begins.

In the other conditions in Pearlmutter and Gibson's study, the word would appeared in the middle clause and a past tense verb appeared in the highest clause.

Crucially, Pearlmutter and Gibson (2001), having asked participants to rate sentences on a 5 -point scale $(1=$ good $/$ easy to $5=$ bad/difficult), found a significant difference in ratings between middle-clause attachment $(M=2.73)$ and high-clause attachment $(M=3.04)$. In subsequent studies, Pearlmutter and Gibson found a reading time difference for sentences disambiguated by reflexives, like Sentence 8 .

(8) The anchorwoman reported that the investors announced that the salesman patented the device to ensure herself/themselves/himself a place on the advisory board.

In three self-paced reading studies, reading times showed a numerical advantage for middle-attachment sentences over high-attachment sentences. The advantage was significant by subjects in Experiment 2, by both subjects and items in Experiment 3, and by items only in Experiment 4.

Why should the highest attachment clause be the second most preferred analysis for complex NP examples but not for VP modification? It is not entirely clear, but one possibility is that speakers tend to avoid sentences in which the modifier of the highest VP comes all the way at the end of the sentence if an alternative structure in which the modifier is located at the beginning of the sentence exists, as in 9A and 9B. By preposing the modifier to the beginning of the sentence, the speaker would produce a sentence that would be easy to understand and that would essentially force the high-attachment reading.

(9A) Next May before any casting begins, the newspaper would print ... (Pearlmutter \& Gibson, 2001, Experiment 1)

(9B) To assure herself a place on the advisory board, the anchorwoman ... (Pearlmutter \& Gibson, 2001, Experiments 2-4)

The idea that listeners and readers are sensitive to the structures that are available to speakers for expressing their meanings is independently required. Gricean approaches to implicature calculation require precisely this assumption; for example, being able to infer that "some students left" implies that "not all students left" requires the listener/reader to recognize that, had all the students left, the speaker could have said so, if indeed it was the case.

Are there alternative accounts of the present findings, apart from an account based on a syntactic recency principle and a pragmatic, relativized relevance/main assertion principle? In a constraint satisfaction model, this will presumably depend on precisely what constraints are included in a model and how they are weighted. We are not aware of a specific model that predicts the effect in ad- vance, but we are also not aware of any inherent problem that would prevent modeling the results in a constraint satisfaction model.

Turning again to SPLT/DLT and whether either of these theories can account for the present findings, we argue that the answer depends on precisely what one takes the theory to be. Both theories postulate a memory cost and an integration cost. SPLT (Gibson, 1998) also assumes that there is no cost for the highest or main clause predicate, presumably because every sentence must have one. However, other predicates, such as those in subordinate clauses, are assumed to impose a memory cost. Thus, abstractly, if integration costs and memory costs interact, then it might be more costly to compute a distant attachment in a subordinate clause than in a main clause. Thus, this approach might offer an account of the data. However, in DLT (Gibson, 2000, and later), the stipulation that matrix predicates did not impose a memory cost was dropped, since it was rather ad hoc. Therefore, to our knowledge, in DLT there is no difference between main clauses and subordinate clauses. Where this matters most, as was pointed out to us several years ago by Tessa Warren (personal communication, 2002), is in sentences like Sentence 10, in which the highest memory cost should, according to SPLT, be at senator, since the matrix predicate does not impose a cost, whereas according to DLT, the cost should be at the verb bothered. The DLT prediction, not the SPLT prediction, seems to be the one that is empirically confirmed.

(10) The fact that the reporter who the senator attacked met the businessman bothered the girl.

Also in DLT, memory costs do not increase with distance (as they do in SPLT). Given this, one might assume that the memory cost is simply a matter of entering a predicted obligatory constituent into, say, the representation of the sentence. But if this prediction has already been entered (for a subordinate clause predicate), then why should it interact with integration? It would seem more likely that a one-time, nonincreasing memory/prediction cost would be incurred at the point when the prediction is noted.

\section{CONCLUSION}

We suggest that the present results illustrate the need for a relativized relevance/main assertion principle, or something similar. On this type of account, simplicity and recency preferences (as in the classic garden path account; Frazier, 1979) are balanced by pragmatic preferences that, when possible, incoming material should be analyzed in whatever way allows it to be relevant to the main assertion. The question of why listeners and readers would treat material this way has two sides: a comprehension side (the expectations that comprehenders have) and a production side (the reasons that producers tend to place important information in particular syntactic positions).

Turning to comprehension first, the recency and main assertion/relativized relevance principles appear to reflect the salience of material in the syntactic and discourse representations, respectively. Generally, the recency preference has been attributed to the strong effects of memory 
decay on syntactic representations, presumably because syntactic representations convey meaning but are not themselves linked into meaningful structures anchored in world knowledge. Hence, the representation of syntax in memory is more fleeting than is the meaning conveyed by that structure (Sachs, 1967). In semantic and discourse representation, in contrast, the salience of material may be determined more by the importance of the material in context (and, presumably, it is influenced by the goals of the speaker/author and listener/reader). Other things being equal, the most accessible material should be the material presented by the speaker in the place where important and focused information is expected to appear. It is this difference between syntax and interpretation that we suspect underlies the recency preference and the main assertion preference. What this means is that in circumstances in which the main assertion principle does not come into play, the low/recent attachment preference should be observed. Conversely, in circumstances in which only one of the potential attachment sites would allow the ambiguous phrase to be relevant to the main assertion, and that site is not the lowest/most recent attachment site, then the syntactic low-attachment preference should be attenuated.

Assuming that the main assertion of a sentence is typically expressed in its main clause, not in a subordinate or relative clause, relativized relevance favors attachment of the PP to the first verb of the experimental sentences in the present study, essentially for pragmatic reasons. On the present account, this preference should be strengthened under conditions in which, for example, the first verb carries a pitch accent and thus may be assumed by the listener to be focused. Indeed, Carlson, Frazier, Clifton, and Dickey (2005) have presented evidence supporting this conclusion.

Presumably, the reason that listeners/readers expect important information to be presented in particular syntactic positions may be attributed to the behavior of speakers/ authors. A speaker/author does not arbitrarily encode propositional meaning in syntactic form. For example, in a series of studies by Tomlin (1997), visual cues were used to draw speakers' attention to either the agent or the recipient of an action in an animated sequence. If attention was drawn to the initiator of an action, speakers produced an active sentence with the agent in the grammatical subject position. If attention was drawn to the recipient of the action, speakers produced a passive sentence with the recipient of the action as the grammatical subject. In choosing a syntactic frame, speakers do not capriciously place important information in syntactic positions subordinate to the positions of less important information.

One issue we have not addressed here is whether the principles under discussion apply to categories other than PPs and VPs (see the discussion of the main assertion hypothesis in studies of VP ellipsis in the introduction). With respect to modifiers of nouns, at least in the case of examples like the daughter of the colonel, a tendency has been observed for both PP and relative clause modifiers to lose a low-attachment preference or even ultimately to prefer attachment to the higher noun-that is, the one involved in the main assertion of the sentence (this tendency has been observed more strongly in Italian-see De Vincenzi \& Job, 1993, 1995-and more ambiguously in English, as noted above; see also Traxler et al., 1998, as well as the original discussion of relativized relevance in Frazier, 1990, and Frazier \& Clifton, 1996). Thus, results to date suggest that relativized relevance applies not only to PPs but to all syntactic categories, just as recency does.

\section{AUTHOR NOTE}

The authors thank Jason Golubock, Lori Miyasato, and Kristen Tooley for assistance in data collection and three anonymous reviewers for helpful comments on the manuscript. This research was supported by National Institutes of Health (NIH) Award 1R01HD048914-01A2 and National Science Foundation Award 0446618 to the first author and by NIH Grants HD18708 and HD 17246 to the University of Massachusetts. Correspondence concerning this article should be addressed to M. J. Traxler, Department of Psychology, University of California at Davis, 1 Shields Avenue, Davis, CA 95616 (e-mail: mjtraxler@ucdavis.edu).

\section{REFERENCES}

Altmann, G. T. M., \& Steedman, M. (1988). Interaction with context during human sentence processing. Cognition, 30, 191-238.

Blozis, S. A., \& TraXler, M. J. (2007). Analyzing individual differences in sentence processing performance using multilevel models. Behavior Research Methods, 39, 31-38.

Brysbaert, M., \& Mitchell, D. C. (1996). Modifier attachment in sentence parsing: Evidence from Dutch. Quarterly Journal of Experimental Psychology, 49A, 664-695.

Carlson, K., Frazier, L., Clifton, C., Jr., \& Dickey, M. W. (2005, April). How contrastive is contrastive focus? Paper presented at the 18th Annual CUNY Sentence Processing Conference, Tucson, AZ.

Clifton, C., Jr., Speer, S., \& Abney, S. P. (1991). Parsing arguments: Phrase structure and argument structure as determinants of initial parsing decisions. Journal of Memory \& Language, 30, 251-271.

Crain, S., \& Steedman, M. J. (1985). On not being led up the garden path: The use of context by the psychological syntax processor. In D. R. Dowty, L. Karttunen, \& A. M. Zwicky (Eds.), Natural language parsing (pp. 320-358). Cambridge: Cambridge University Press.

De Vincenzi, M., \& Job, R. (1993). Some observations on the universality of the late-closure strategy. Journal of Psycholinguistic Research, 22, 189-206.

De VincenZI, M., \& Job, R. (1995). An investigation of late closure: The role of syntax, thematic structure, and pragmatics in initial interpretation. Journal of Experimental Psychology: Learning, Memory, \& Cognition, 21, 1303-1321.

FoDOR, J. D. (1998). Learning to parse. Journal of Psycholinguistic Research, 27, 285-319.

FoDOR, J. D. (2002). Prosodic disambiguation in silent reading. Proceedings of the North East Linguistic Society, 32, 112-132.

Ford, M., BResnan, J. W., \& Kaplan, R. M. (1982). A competencebased theory of syntactic closure. In J. W. Bresnan (Ed.), The mental representation of grammatical relations (pp. 727-796). Cambridge, MA: MIT Press.

FrAZIER, L. (1979). On comprehending sentences: Syntactic parsing strategies. Unpublished doctoral dissertation, University of Connecticut, Storrs.

FrAZIER, L. (1989). Against lexical generation of syntax. In W. MarslenWilson (Ed.), Lexical representation and process (pp. 505-528). Cambridge, MA: MIT Press.

FrAZIER, L. (1990). Parsing modifiers: Special purpose routines in the human sentence processing mechanism? In D. Balota, G. B. Flores d'Arcais, \& K. Rayner (Eds.), Comprehension processes in reading (pp. 303-330). Hillsdale, NJ: Erlbaum.

Frazier, L., \& Clifton, C., JR. (1996). Construal. Cambridge, MA: MIT Press.

Frazier, L., \& Clifton, C., JR. (2005). The syntax-discourse divide: Processing ellipsis. Syntax, 8, 121-174.

Gibson, E. (1998). Linguistic complexity: Locality of syntactic dependencies. Cognition, 68, 1-76. 
GiBSON, E. (2000). The dependency locality theory: A distance-based theory of linguistic complexity. In A. Marantz, Y. Miyashita, \& W. O'Neil (Eds.), Image, language, brain: Papers from the First Mind Articulation Project Symposium (pp. 95-126). Cambridge, MA: MIT Press.

Gibson, E., Pearlmutter, N., Canseco-Gonzalez, E., \& Hickok, G. (1996). Recency preference in the human sentence processing mechanism. Cognition, 59, 23-59.

Gilboy, E. J., Sopena, M., Clifton, C., JR., \& Frazier, L. (1995). Argument structure and association preferences in Spanish and English compound NPs. Cognition, 54, 131-167.

JACKENDOFF, R. (2007). A parallel architecture perspective on language processing. Brain Research, 46, 2-22.

MacDonald, M. C., Pearlmutter, N. J., \& Seidenberg, M. S. (1994). The lexical nature of syntactic ambiguity resolution. Psychological Review, 101, 676-703.

Mitchell, D. C. (1987). Lexical guidance in human parsing: Locus and processing characteristics. In M. Coltheart (Ed.), Attention and performance XII (pp. 601-618). Hillsdale, NJ: Erlbaum.

Mitchell, D. C., Cuetos, F., Corley, M. M. B., \& Brysbaert, M. (1995). Exposure-based models of human parsing: Evidence for the use of coarse-grained (nonlexical) statistical records. Journal of Psycholinguistic Research, 24, 469-488.

Pearlmutter, N. J., \& Gibson, E. (2001). Recency in verb phrase attachment. Journal of Experimental Psychology: Learning, Memory, \& Cognition, 27, 574-590.

Pickering, M. J., \& TraXler, M. J. (2003). Evidence against the use of subcategorisation frequency in the processing of unbounded dependencies. Language \& Cognitive Processes, 18, 469-503.

RAUDENBUSH, S. W., \& BRYK, A. S. (2002). Hierarchical linear models: Applications and data analysis methods (2nd ed.). Thousand Oaks, CA: Sage.

SACHS, J. S. (1967). Recognition memory for syntactic and semantic aspects of connected discourse. Dissertation Abstracts International, 27, 2900.

Schutze, C., \& Gibson, E. (1999). Argumenthood and English prepositional phrase attachment. Journal of Memory \& Language, 40, 409-431.

Staub, A., Clifton, C., JR., \& Frazier, L. (2005, April). Subcategorization possibilities trigger syntactic expectations: Evidence from processing heavy noun phrase shift. Poster presented at the 18th Annual CUNY Sentence Processing Conference, Tucson, AZ.
Tanenhaus, M. K., Spivey-Knowlton, M. J., Eberhard, K. M., \& SEDIVY, J. C. (1995). Integration of visual and linguistic information in spoken language comprehension. Science, 268, 1632-1634.

Taraban, R., \& McClelland, J. L. (1988). Constituent attachment and thematic role assignment in sentence processing: Influences of contentbased expectations. Journal of Memory \& Language, 27, 597-632.

ToMLIN, R. S. (1997). Mapping conceptual representations into linguistic representations: The role of attention in grammar. In J. Nuyts \& E. Pederson (Eds.), Language and conceptualization (pp. 162-189). Cambridge: Cambridge University Press.

TraXler, M. J. (2002). Plausibility and subcategorization preference in children's processing of temporarily ambiguous sentences: Evidence from self-paced reading. Quarterly Journal of Experimental Psychology, 55A, 75-96.

TraXler, M. J. (2005). Plausibility and verb subcategorization preference in temporarily ambiguous sentences. Journal of Psycholinguistic Research, 34, 1-30.

Traxler, M. J., Pickering, M. J., \& Clifton, C., Jr. (1998). Adjunct attachment is not a form of lexical ambiguity resolution. Journal of Memory \& Language, 39, 558-592.

Trueswell, J. C., SeKerina, I., Hill, N. M., \& Logrip, M. L. (1999). The kindergarten-path effect: Studying on-line sentence processing in young children. Cognition, 73, 89-134.

Trueswell, J. [C.], Tanenhaus, M. K., \& Kello, C. (1993). Verbspecific constraints in sentence processing: Separating effects of lexical preference from garden-paths. Journal of Experimental Psychology: Learning, Memory, \& Cognition, 19, 528-553.

Van Gompel, R. P. G., Pickering, M. J., \& Traxler, M. J. (2000). Unrestricted race: A new model of syntactic ambiguity resolution. In A. Kennedy (Ed.), Reading as a perceptual process (pp. 621-648). Amsterdam: Elsevier.

Van Gompel, R. P. G., Pickering, M. J., \& Traxler, M. J. (2001). Reanalysis in sentence processing: Evidence against current constraintbased and two-stage models. Journal of Memory \& Language, 45, $225-258$

\section{NOTE}

1. Note that the presence or absence of a comma did not improve the model fits or interact with the other variables and therefore that factor does not appear in the analyses reported here.

\section{APPENDIX}

\section{Subordinate Clause Sentences}

Sentences were presented double spaced.

Before the baker delivered the bread that he checked to the store (on the corner), the customer stopped by for some donuts.

Before the baker checked the bread that he delivered to the store (on the corner), the customer stopped by for some donuts.

After the patrolman offered the report that he typed to the detective (supervisor of the night shift), the chief arrived at the station.

After the patrolman typed the report that he offered to the detective (supervisor of the night shift), the chief arrived at the station.

When Mary brought the apples that she grew to the market (on Main street), the school teacher phoned to arrange a visit.

When Mary grew the apples that she brought to the market (on Main street), the school teacher phoned to arrange a visit.

Although Tony gave the dog that he found to the nurse (on duty), she still wanted another pet.

Although Tony found the dog that he gave to the nurse (on duty), she still wanted another pet.

As John told the story that he bungled to the teacher (in the green dress), the students fidgeted in their seats.

As John bungled the story that he told to the teacher (in the green dress), the students fidgeted in their seats.

Long after George taught the song that he learned to the cub scouts (from Bakersfield), they would sing it at the top of their voices. 


\section{APPENDIX (Continued)}

Long after George learned the song that he taught to the cub scouts (from Bakersfield), they would sing it at the top of their voices.

Long before the teacher assigned the book that she forgot to the class (of English literature students), the students learned about Shakespeare.

Long before the teacher forgot the book that she assigned to the class (of English literature students), the students learned about Shakespeare.

Shortly after Mike donated the money that he earned to the church (built in 1905), the minister ordered a huge stained glass window.

Shortly after Mike earned the money that he donated to the church (built in 1905), the minister ordered a huge stained glass window.

Shortly before Jason left the stock that he inherited to the museum (of modern art), the curator unpacked the newly arrived portraits.

Shortly before Tony inherited the stock that he left to the museum (of modern art), the curator unpacked the newly arrived portraits.

While Sandy wrote the note that she hid to her friends (of many years), the burglar squeezed through the basement window.

While Sandy hid the note that she wrote to her friends (of many years), the burglar squeezed through the basement window.

Even though Joan recommended the soup that she ordered to the customers (from Reno), they chose to eat sandwiches instead.

Even though Joan ordered the soup that she recommended to the customers (from Reno), they chose to eat sandwiches instead.

Just before the shortstop threw the ball that he signed to the kids (from the orphanage), the umpire brushed the dirt off of home plate.

Just before the shortstop signed the ball that he threw to the kids (from the orphanage), the umpire brushed the dirt off of home plate.

A long time after the old man willed the house that he built to the family (of strangers), the banker foreclosed on the loan.

A long time after the old man built the house that he willed to the family (of strangers), the banker foreclosed on the loan.

Well after the lawyer returned the money that he stole to the IRS (bank on Front Street), the investigator reported his findings to the police.

Well after the lawyer stole the money that he returned to the IRS (bank on Front Street), the investigator reported his findings to the police.

Just after the driver sent the package that he collected to the store (near the fire station), the clerk recorded the delivery in the log book.

Just after the driver collected the package that he sent to the store (near the fire station), the clerk recorded the delivery in the log book.

After the DJ played the CDs that he recorded to the listeners (at home), the switchboard at the station lit up like a Christmas tree.

After the DJ recorded the CDs that he played to the listeners (at home), the switchboard at the station lit up like a Christmas tree.

Before the pilot flew the plane that he tested to the airport (airstrip connected to LAX), the mechanic checked the oil level in the engine.

Before the pilot tested the plane that he flew to the airport (airstrip connected to LAX), the mechanic checked the oil level in the engine.

When the builder dragged the tool that he made to the site (near the mill), the carpenter brought the lumber from the mill.

When the builder made the tool that he dragged to the site (near the mill), the carpenter brought the lumber from the mill.

Although the journalist surrendered the notes that he copied to the police (policeman on patrol), the judge decided to hold him in contempt.

Although the journalist copied the notes that he surrendered to the police (policeman on patrol), the judge decided to hold him in contempt.

Even though the young man confessed the sins that he regretted to the priest (of the parish), the victim did not forgive him. 


\section{APPENDIX (Continued)}

Even though the young man regretted the sins that he confessed to the priest (of the parish), the victim did not forgive him.

Just before the assistant exposed the students that he trusted to the professor (of philosophy), the dean gave a lecture on ethics.

Just before the assistant trusted the students that he exposed to the professor (of philosophy), the dean gave a lecture on ethics.

As David whispered the joke that he remembered to the girl (from the tenth grade), the other people in the movie theater told him to be quiet.

As David remembered the joke that he whispered to the girl (from the tenth grade), the other people in the movie theater told him to be quiet.

Long after Mark shipped the package that he wrapped to the lawyer (on the case), the secretary phoned to ask about the documents.

Long after Mark wrapped the package that he shipped to the lawyer (on the case), the secretary phoned to ask about the documents.

Not long before Jennifer forwarded the message that she received to the supervisor (of the night shift), the foreman complained about the new equipment.

Not long before Jennifer received the message that she forwarded to the supervisor (of the night shift), the foreman complained about the new equipment.

Because the girl chased the singer that she loved to the limousine (parked outside), the bodyguard worried about the singer's safety.

Because the girl loved the singer that she chased to the limousine (parked outside), the bodyguard worried about the singer's safety.

Shortly after the detective followed the suspect that he photographed to the warehouse (painted black), the smugglers arrived with suitcases full of money.

Shortly after the detective photographed the suspect that he followed to the warehouse (painted black), the smugglers arrived with suitcases full of money.

Just after the senior led the junior that she irritated to the classroom (on the third floor), the fire alarm went off.

Just after the senior irritated the junior that she led to the classroom (on the third floor), the fire alarm went off.

Shortly before the beer man tossed the peanuts that he picked up to the fan (in the front row), the third baseman hit a towering home run.

Shortly before the beer man picked up the peanuts that he tossed to the fan (in the front row), the third baseman hit a towering home run.

\section{Main Clause Sentences}

All sentences were presented double spaced. The material in parentheses was used so that a comma would appear immediately after the scoring region (e.g., Item 2 would read: offered the report that he typed to the detective, because he needed to read it). The comma and the following clause replaced the material that appears here in italics.

The baker delivered the bread that he checked to the store because they were running out. (, but it was too late.)

The baker checked the bread that he delivered to the store because they were running out. (, but it was too late.)

The patrolman offered the report that he typed to the detective so he would read it. (, because he needed to read it.)

The patrolman typed the report that he offered to the detective so he would read it. (, because he needed to read it.)

Mary brought the apples that she grew to the market in order to trade them for some eggs. (, which was located at the edge of town.)

Mary grew the apples that she brought to the market in order to trade them for some eggs. (, which was located at the edge of town.)

Tony gave the dog that he found to the nurse so she could check to see if he had rabies. (, and she checked to see if it had rabies.)

Tony found the dog that he gave to the nurse so she could check to see if he had rabies. (, and she checked to see if it had rabies.)

John told the story that he bungled to the teacher to try and make her laugh. (, but she wasn't listening.)

John bungled the story that he told to the teacher to try and make her laugh. (, but she wasn't listening.)

Robin taught the song that he learned to the cub scouts so that they would have something to do. (, because they were bored.) 


\section{APPENDIX (Continued)}

Robin learned the song that he taught to the cub scouts so that they would have something to do. (, because they were bored.)

The teacher assigned the book that she forgot to the class so they could learn about poetry. (, and they were annoyed.)

The teacher forgot the book that she assigned to the class so they could learn about poetry. (, and they were annoyed.)

Mike donated the money that he earned to the church so he could get a tax write off. (, so the roof got replaced.)

Mike earned the money that he donated to the church so he could get a tax write off. (, so the roof got replaced.)

Tony left the stock that he inherited to the museum because it was what his grandmother would have wanted. (, because it was what his grandmother would have wanted.)

Tony inherited the stock that he left to the museum because it was what his grandmother would have wanted. (, because it was what his grandmother would have wanted.)

Sandy wrote the note that she hid to her friends because she was feeling sad. (, because she was feeling sad.)

Sandy hid the note that she wrote to her friends because she was feeling sad. (, because she was feeling sad.)

Joan recommended the soup that she ordered to the customer instead of the salad. (, but he wanted the salad instead.)

Joan ordered the soup that she recommended to the customer instead of the salad. (, but he wanted the salad instead.)

The shortstop threw the ball that he signed to the kids so they would fight over who got to keep it. (, and they fought over who got to keep it.)

The shortstop signed the ball that he threw to the kids so they would fight over who got to keep it. (, and they fought over who got to keep it.)

The old man willed the house that he built to the family because they needed a place to stay. (, because they needed a place to stay.)

The old man built the house that he willed to the family because they needed a place to stay. (, because they needed a place to stay.)

The lawyer returned the money that he stole to the IRS to try and avoid going to jail. (, but they sent him to jail anyway.)

The lawyer stole the money that he returned to the IRS to try and avoid going to jail. (, but they sent him to jail anyway.)

The driver sent the package that he collected to the store because the customer hated the goods. (, because the customer hated the goods.)

The driver collected the package that he sent to the store because the customer hated the goods. (, because the customer hated the goods.)

The DJ played the CDs that he recorded to the listeners because of the manager's instructions. (, because of the manager's instructions.)

The DJ recorded the CDs that he played to the listeners because of the manager's instructions. (, because of the manager's instructions.)

The pilot flew the plane that he tested to the airport so he could get a better feel for the weather conditions. (, so he could get a better feel for the weather conditions.)

The pilot tested the plane that he flew to the airport so he could get a better feel for the weather conditions. (, so he could get a better feel for the weather conditions.)

The builder dragged the tool that he made to the site in order to fix the roof. (, so he could fix the roof.)

The builder made the tool that he dragged to the site in order to fix the roof. (, so he could fix the roof.)

The journalist surrendered the notes that he copied to the police to avoid being prosecuted. (, and they decided not to prosecute.)

The journalist copied the notes that he surrendered to the police to avoid being prosecuted. (, and they decided not to prosecute.)

The young man confessed the sins that he regretted to the priest to please his mother. (, who was shocked and upset.)

The young man regretted the sins that he confessed to the priest to please his mother. (, who was shocked and upset.)

The assistant exposed the students that he trusted to the professor for cheating on their final exam. (, because he thought they had cheated on the final exam.) 


\section{APPENDIX (Continued)}

The assistant trusted the students that he exposed to the professor for cheating on their final exam. (, because he thought they had cheated on the final exam.)

David whispered the joke that he remembered to the girl in order to get a date with her. (, but she didn't think it was very funny.)

David remembered the joke that he whispered to the girl in order to get a date with her. (, but she didn't think it was very funny.)

Mark shipped the package that he wrapped to the lawyer trusting the FBI would not catch him. (, trusting the FBI would not catch him.)

Mark wrapped the package that he shipped to the lawyer trusting the FBI would not catch him. (, trusting the FBI would not catch him.)

Jennifer forwarded the message that she received to the supervisor and implied that she wasn't appreciated. (, and implied that she wasn't appreciated.)

Jennifer received the message that she forwarded to the supervisor and implied that she wasn't appreciated. (, and implied that she wasn't appreciated.)

The girl chased the singer that she loved to the limousine which caused her boyfriend to get very angry. (, which caused her boyfriend to get very angry.)

The girl loved the singer that she chased to the limousine which caused her boyfriend to get very angry. (, which caused her boyfriend to get very angry.)

The detective followed the suspect that he photographed to the warehouse to find out where the jewels were. (, which had been searched the day before.)

The detective photographed the suspect that he followed to the warehouse to find out where the jewels were. (, which had been searched the day before.)

The senior led the junior that she irritated to the classroom because he wanted to ask her to the dance. (, because he wanted to ask her to the dance.)

The senior irritated the junior that she led to the classroom because he wanted to ask her to the dance. (, because he wanted to ask her to the dance.)

The beer man tossed the peanuts that he picked up to the fan because he couldn't reach that far. (, because he couldn't reach that far.)

The beer man picked up the peanuts that he tossed to the fan because he couldn't reach that far. (, because he couldn't reach that far.) 